\title{
Ein kultivierter Haudegen auf Verbrecherjagd
}

\section{Interview: Isabel Zwyssig}

M.A., koordinierende Redaktorin

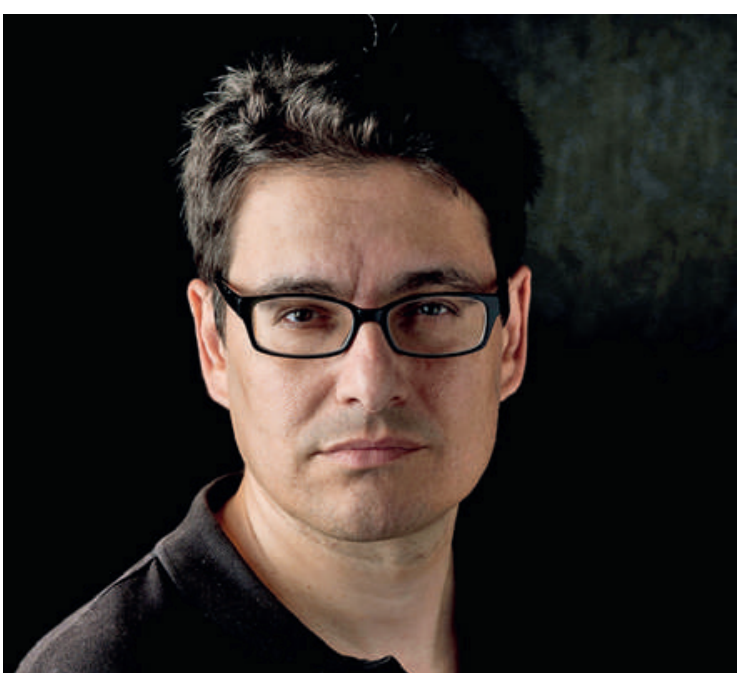

Setzt sich kritisch mit seiner sozialen und politischen Umwelt auseinander: Arzt und Krimiautor Telemachos Hatziisaak.

Herr Dr. Hatziisaak, nach Kalte Allianz (2011) und Sabotageakt (2013), erscheint 2015 im Verlag Johannes Petri bereits der dritte Krimi, Hasardeur, mit Kommissar Nikos Pavlides in der Hauptrolle. Was fasziniert Sie an dieser Figur? Nikos Pavlides ist der erste smarte, scharfsinnige griechische Kommissar der Kriminalliteratur. Er ist hartnäckig, aber nicht verbissen. Cool, aber nicht hochnäsig. Selbstkritisch, aber nicht grüblerisch. Er arbeitet - ganz «ungriechisch», würde man meinen - strukturiert und ergebnisorientiert, getrieben von der Frage nach dem «Cui bono?». Letztere Eigenschaft ist jedoch typisch griechisch. Ausserdem verfügt Pavlides über einen ausgesprochenen Gerechtigkeitssinn, wodurch er bei seinen Ermittlungen bisweilen in Teufels Küche gerät. Er ist sozusagen ein kultivierter Haudegen. Solche Figuren, die es durchaus auch im echten Leben gibt, faszinieren mich.

\section{Vernissage}

Die Vernissage zum Buch findet statt am 26. November um 19 Uhr in der Buchhandlung "Das Narrenschiff» an der Steinentorstrasse 11 in Basel. Weitere Informationen zur Veranstaltung finden Sie auf der Homepage des Verlags Johannes Petri.
Ihr Protagonist bewegt sich im Spannungsfeld zwischen Terror, Geheimdiensten und staatlichen Interessen. Unter anderem spielen in Ihrem dritten Roman Folterskandale in amerikanischen Gefängnissen eine Rolle. Inwiefern beeinflussen politische Belange die Konzeption Ihrer Romanhandlungen? Bei den Pavlides-Romanen handelt es sich um eine Politkrimi-Serie. In meinem Wertesystem muss Kunst, also auch Literatur, aufklärerisch und politisch sein. Wir alle sind politische Menschen. Menschen, die in einem sozialen Gefüge, einer «Polis» verankert sind. Es ist unsere existenzielle Pflicht, uns kritisch damit auseinander zu setzen. In meinem Fall geschieht dies als Recherche und Reflexion über politische Ereignisse und Tatsachen der jüngsten Vergangenheit, z.B. über CIA-Geheimgefängnisse, die ich als Kontext für die fiktiven Handlungen meines aktuellen Politkrimis verwende.

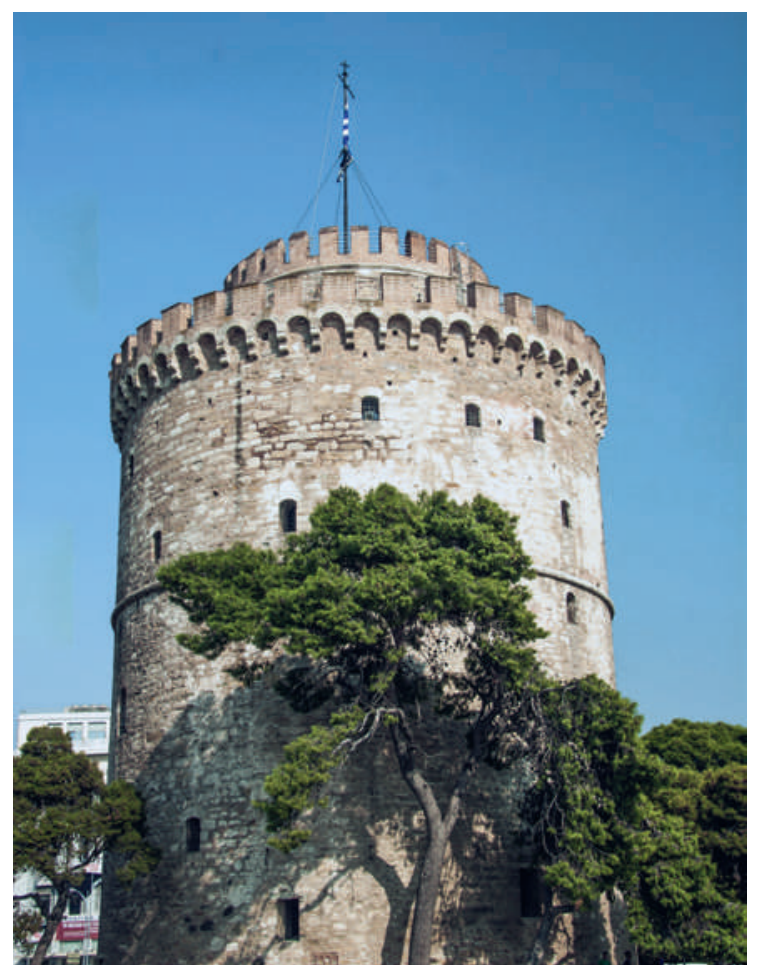

Thessaloniki, ein wichtiger Schauplatz in Hatziisaaks drittem Kriminalroman. Der weisse Turm ist ein charakteristisches Baudenkmal der griechischen Stadt. 
Wie dient Ihr beruflicher Alltag als Arzt als Inspirationsquelle zum Schreiben?

Als Hausarzt erleben Sie täglich Menschen in ihrer individuellen Vielfalt, in ihren stereotypen Handlungsmustern. Sie erfahren von ihren Krankheiten, Schwächen, Lastern und lernen, die Menschen so zu akzeptieren, wie sie sind. Der Kontakt zu den verschiedensten Menschen ist selbstredend eine der wichtigsten Inspirationsquellen für die Beschreibung von Charakteren in der Literatur, wozu ich auch zeitgenössische Kriminalromane zähle. Aber auch ganz konkret fliesst mein Alltag in den aktuellen Roman ein: Pavlides' Assistentin, Penelope Livanou, ist Typ-1-Diabetikerin.

Sie bewegen sich in Ihrem beruflichen Selbstverständnis als Arzt und Autor zwischen zwei Polen. Auch kulturell sind Sie in zwei unterschiedlichen Welten zugleich verhaftet: in der schweizerischen und in der griechischen. Wie beurteilen Sie vor diesem Hintergrund die Entwicklung, die Sie als Krimiautor durchlaufen haben?

Dialektik - im Sinne eines Diskurses zwischen These und Antithese - ist für mich ein Schlüsselbegriff. Ich habe nie das Gefühl, ich sässe als Person oder als Autor zwischen Stuhl und Bank. Vielmehr suche ich die Synthese und betone die Gemeinsamkeiten in den Unterschieden. So zum Beispiel in meinem ersten Roman, Kalte Allianz, wo ich den Griechen Nikos Pavlides gemeinsam mit einer türkischen Kommissarin ermitteln lasse. Oder im aktuellen Krimi Hasardeur, in dem ich dem smarten Nikos Pavlides eine «noch smartere» Assistentin zur Seite stelle, die darüber hinaus ein vermeintliches Handicap hat: den Typ-1-Diabetes. Mein Augenmerk liegt stets auf dem Einenden, aber auch auf der Betonung der Stärke des vermeintlich Schwachen. Ein Leitgedanke des politisierten Roman noir.

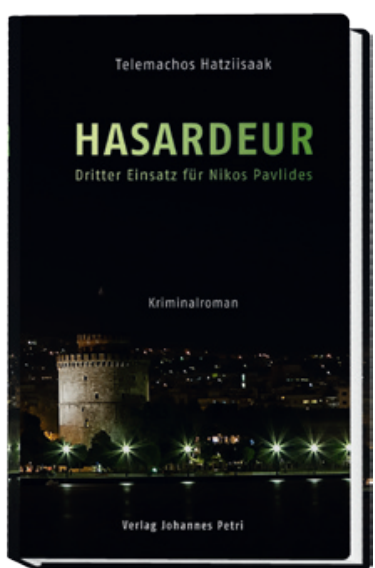

Telemachos Hatziisaak

Hasardeur

Dritter Einsatz für Nikos Pavlides

Basel: Verlag Johannes Petri; 2015.

320 Seiten. 28 CHF.

ISBN 978-3-03784-073-3

\section{Über das Buch}

Thessaloniki, im Sommer 2004. Telemachos Hatziisaak schickt seine Hauptfigur, Kommissar Nikos Pavlides, auf die gefährliche Jagd nach Griechenlands meistgesuchtem, skrupellosestem Verbrecher Zyssis Mafoutis. Unterstützt wird Pavlides dabei von einer völlig unerfahrenen, jungen Kollegin: der Juristin Penelope Livanou. Tage später wird an einem Enthüllungsjournalisten, Autor einer Aufsehen erregenden Reportage über Folter in einem CIA-Geheimgefängnis, ein geheimnisvoller Mordfall verübt. Kurz darauf ereignet sich ein weiteres Tötungsdelikt. Auf einmal taucht Mafoutis auf. Welche Verbindungen gibt es zwischen den Mordfällen, dem plötzlichen Erscheinen des Verbrechers und dem Folterskandal? Kommissar Nikos Pavlides und seine Assistentin Penelope Livanou nehmen die Ermittlungen auf. So manche Situation treibt die beiden an ihre Grenzen, und manchmal gelingt es ihnen nur knapp, den Kopf aus der Schlinge zu ziehen.

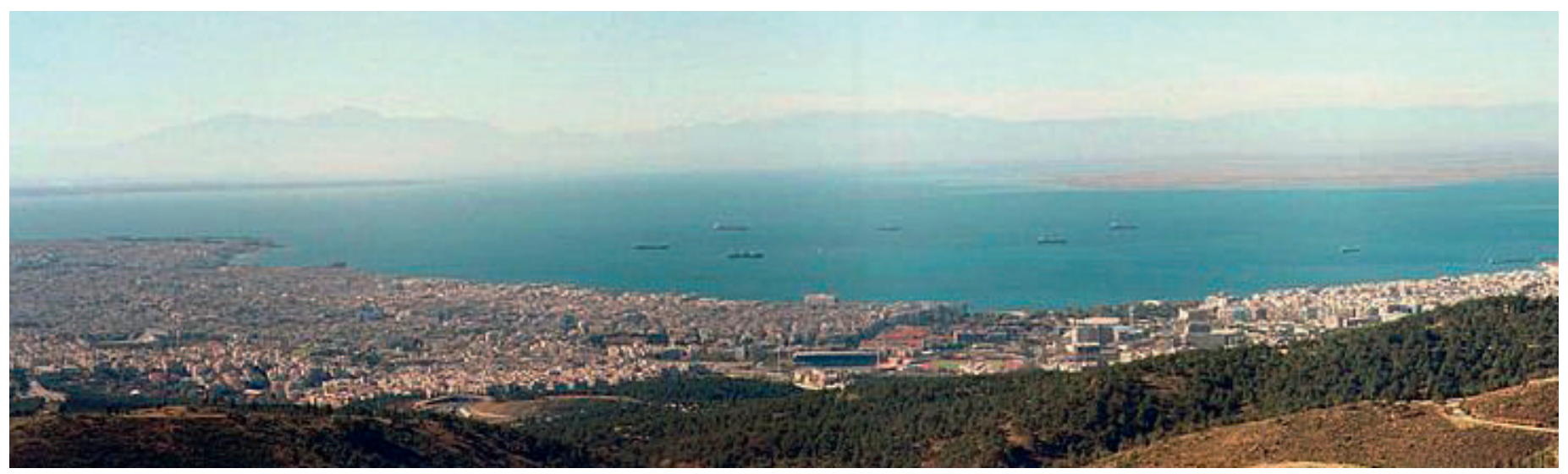

Das Panorama von Thessaloniki mit dem Olymp-Massiv im Hintergrund. 